\title{
Rate of NDF degradation
}

\author{
M.R. Weisbjerg ${ }^{1,3}$, V. Koukolová ${ }^{2}$ and P. Lund ${ }^{1}$ \\ ${ }^{1}$ Faculty of Agricultural Sciences, University of Aarhus, Research Centre Foulum \\ P.O. Box 50, DK-8830 Tjele, Denmark \\ ${ }^{2}$ Institute of Animal Science \\ Přátelství 815, 10400 Praha-Uhřiněves, Czech Republic
}

\begin{abstract}
Degradation profiles for NDF were estimated for 83 samples of grass/grass-clover, 27 samples of cereal whole crop and 14 samples of maize whole crop. To examine variation in rate of degradation, degradation profiles were analysed for rate of degradation in individual incubation intervals. For grass/grass-clover and maize whole crop, rate of degradation first increased and then decreased with increasing incubation time, especially for grass/grass-clover, indicating both a lag time before maximum degradation is reached, and multiple NDF pools with different rates of degradation. In contrast, whole crop cereals had a very high degradation rate in the first incubation interval, and thereafter degradation rate decreased, indicating that a small fraction of the NDF in whole crop cereals is very easily degradable. The non constant rate of NDF degradation means that estimated degradation parameters will be very dependent on the degradation times used for parameterization, and therefore standardization of the method used for estimation of degradation characteristics is essential.
\end{abstract}

KEY WORDS: nylon bag, in situ, whole crop cereal, maize whole crop, grass-clover, fractional degradation rate

\section{INTRODUCTION}

Parameters for degradation of nutrients in the rumen are essential in new ration evaluation models. Profiles of nutrient degradation in the rumen are normally estimated using either nylon bag (in situ), in vitro disappearance or in vitro gas production methods. In the new ration evaluation models the nutrient (starch, protein, NDF) degradation profile is assumed to follow first order mass action kinetics. This approach is based on the assumption that a nutrient can be divided

\footnotetext{
${ }^{3}$ Corresponding author: e-mail: Martin.Weisbjerg@agrsci.dk
} 
in a soluble fraction (can be zero), a degradable fraction and an undegradable fraction, and further, that a constant proportion of the remaining of the degradable fraction is degraded per time unit.

The assumption of constant fractional rate of degradation is known not to be fully correct, and inclusion of lag time and multiple pool or non constant degradation rate models improves fitting of degradation data. However, it is important to avoid over parameterization of the model used to describe degradation profiles to be appropriate for practical use in the new ration evaluation models. Generally, these ration evaluation models use parameters describing a soluble fraction, a degradable fraction and a constant fractional rate of degradation, whereas lag time and non constant degradation or multiple pool parameters are seldom used due to the increased complexity. The aim of the present paper is to show the variation in fractional rate of degradation with varying in situ incubation time for some typical forages.

\section{MATERIAL AND METHODS}

NDF degradation profiles for 83 samples of grass and grass/clover (silage, hay and unconserved), 27 samples of whole crop cereals (unconserved and silage of barley and wheat), and 14 samples of maize whole crop (silage and unconserved) were used for this study.

NDF degradation was performed using the in situ method according to Weisbjerg and Hvelplund (2005). Samples were freeze dried, milled through 1.5 $\mathrm{mm}$ screen and incubated in nylon bags with pore size $37 \mu \mathrm{m}$ (for $288 \mathrm{~h} 12 \mu \mathrm{m}$ ) for $0,2,4,8,24,48,96$ and $168 \mathrm{~h}$ and potential degradability was estimated after 504 or $288 \mathrm{~h}$ incubation. After incubation residues were transferred quantitatively for ash free NDF analysis including amylase treatment.

Degradability was calculated relatively to $0 \mathrm{~h}$ residue to account for eventual particle losses, except for $288 \mathrm{~h}$ incubations where nylon bag pore size and therefore also particle loss was small.

\section{Estimation principles}

Two main methods are used for fitting data to the first-order kinetic models: linear regression on logarithmic transformations of the undigested residues (lnlinear) and nonlinear estimation of degradation parameters. Nonlinear models estimate the parameter values simultaneously and assume equal error at each incubation time, whereas ln-linear models assume the error is proportional to the size of residue at each time. Neither of these approaches seems reasonable, as random errors (and between cow variation) normally are largest at medium (8-48 
h) incubation times. In the ln-linear approach potential digestibility of NDF must be determined experimentally using the data from the longest incubation time, and therefore any error in estimating potential digestibility can bias the values of other parameters (Huhtanen et al., 2006). In the present study the ln-linear approach was used on individual incubation intervals as proposed by van Soest et al. (2000), which allows for estimation of a fractional rate of degradation for each incubation interval. As estimate for potential degradability $\left(f_{d}\right)$, degradabilities obtained after either 288 or $504 \mathrm{~h}$ rumen incubation were used. The reason for two methods was a change in the standard used in our laboratory.

Fractional rate of degradation in incubation intervals between incubation times $t_{x}$ and $t_{x+1}$ is calculated as $\left[\ln \left(f_{d}-\right.\right.$ degradation $\left.\left(t_{x}\right)\right)-\ln \left(f_{d}-\right.$ degradation $\left.\left.\left(t_{x+1}\right)\right)\right] /\left[t_{x+1}-t_{x}\right]$.

\section{RESULTS}

Degradation profiles for the three forage type groups are shown in Figure 1. It is obvious that each forage type includes a broad variety of samples, but also that the degradation profiles differ considerably between forage types.
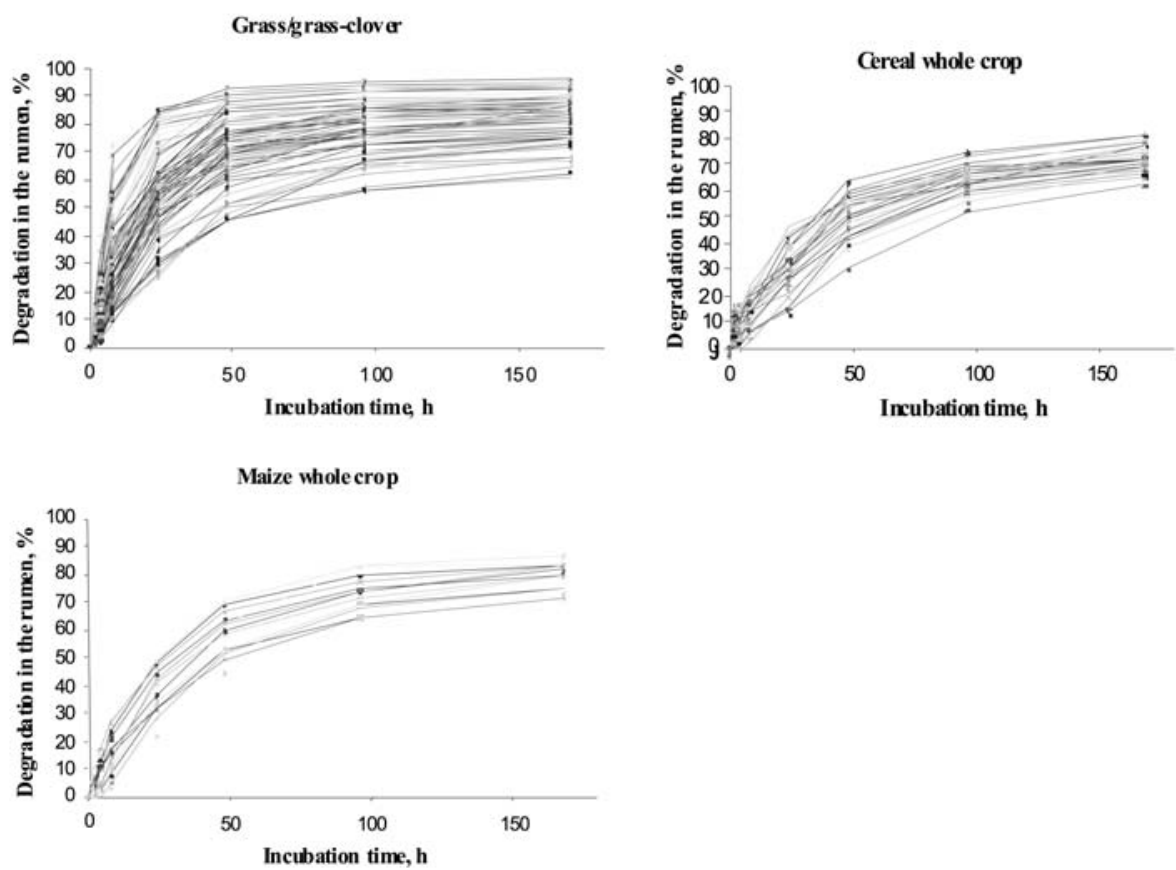

Figure 1. NDF degradation profiles for the grass/grass-clover, cereal whole crop and maize whole crop, for incubation times up to $168 \mathrm{~h}$ 
In Table 1 degradation rates for the individual incubation intervals are shown together with test statistics for effect of forage type and incubation interval, and in Figure 2 the degradation rates are plotted against mean time within incubation interval for cereal whole crop, grass/clover and maize whole crop. For comparison, the fractional rates of degradation for the degradation profile for incubations up to $168 \mathrm{~h}$ are also shown.

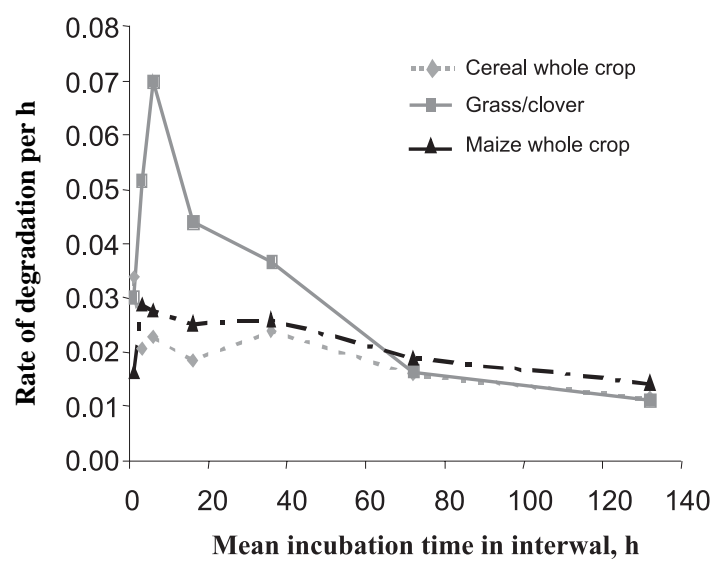

Figure 2. Plot of fractional rate of NDF degradation in the different incubation intervals

The degradation rate differs considerably between incubation intervals for all three forage types, but the effect of incubation time intervals was different for the forage types. For grass/grass-clover and maize silage the degradation rate was low in the first incubation interval, then higher for the next incubation intervals especially for grass/grass-clover and thereafter decreased for long time incubation intervals. However, for maize whole crop the variation between degradation rates in different incubation intervals was not significant. This pattern in degradation rates can be interpreted as a lag in upstart of NDF degradation in the rumen, and that NDF is composited by various pools of NDF with various degradation rates, resulting in a decreasing degradation rate after the lag time.

For whole crop cereals the pattern was different. The degradation rate was high in the first incubation interval (0-2 h) and thereafter decreased and was rather steady for the longer incubation intervals although it decreased slightly for the longest incubation intervals. This must be due to a very easily degradable NDF fraction in these whole crop cereals, as pollution of the NDF with starch should be out ruled by the use of amylase in the NDF boiling process. 
Table 1. Fractional rate of NDF degradation $\left(\mathrm{h}^{-1}\right)$ in the different incubation intervals for three forage types. Tests for effect of time performed within forage type, test for effect of forage type performed within time interval

\begin{tabular}{|c|c|c|c|c|}
\hline $\begin{array}{l}\text { Incubation time interval, } \\
\text { mean in brackets, } \mathrm{h}\end{array}$ & $\begin{array}{c}\text { Grass/grass- } \\
\text { clover } \\
\mathrm{n}=83 \\
\end{array}$ & $\begin{array}{c}\text { Cereal whole } \\
\text { crop } \\
\mathrm{n}=27 \\
\end{array}$ & $\begin{array}{c}\text { Maize whole } \\
\text { crop } \\
n=14\end{array}$ & $\begin{array}{l}\text { P - effect of } \\
\text { feed }\end{array}$ \\
\hline $0-2(1)$ & 0.0301 & 0.0337 & 0.0162 & 0.11 \\
\hline $2-4(3)$ & 0.0515 & 0.0205 & 0.0288 & 0.0002 \\
\hline $4-8(6)$ & 0.0698 & 0.0227 & 0.0275 & $<0.0001$ \\
\hline $8-24(16)$ & 0.0439 & 0.0184 & 0.0252 & $<0.0001$ \\
\hline $24-48(36)$ & 0.0367 & 0.0238 & 0.0259 & $<0.0001$ \\
\hline $48-96(72)$ & 0.0165 & 0.0158 & 0.0188 & 0.3 \\
\hline $96-168(132)$ & 0.0112 & 0.0114 & 0.0142 & 0.3 \\
\hline$P$ - effect of incubation time & $<0.0001$ & 0.0002 & 0.1 & \\
\hline From whole profile $^{1}$ & 0.0511 & 0.0237 & 0.0241 & $<0.0001$ \\
\hline
\end{tabular}

${ }^{1}$ fitted using Proc NLIN in SAS using a simple exponential model including fractional degradation rate and asymptote, but without lag time, and using data for incubations up to $168 \mathrm{~h}$

\section{CONCLUSIONS}

Rate of NDF degradation in the rumen is not constant, as normally assumed in models for describing NDF degradation profiles. Especially for grass/grass-clover both a lag in onset of degradation and a very high degradation rate in the first incubation intervals after the lag is seen, indicating both a lag time and various NDF pools with different degradation rates. Models for NDF degradation which can fit these degradation characteristics become complicated to use in ration evaluation systems, as they include many correlated parameters. However, these results show that if more simple models are used to estimate degradation parameters, it is essential that the methods used are standardized, as variation in e.g., incubation times used will severely affect estimated degradation parameters.

\section{REFERENCES}

Huhtanen P., Ahvenjärvi S., Weisbjerg M.R., Nørgaard P., 2006. Digestion and passage of fibre in ruminants. In: K. Sejrsen, T. Hvelplund, M.O. Nielsen (Editors). Ruminant Physiology, Digestion, Metabolism and Impact of Nutrition on Gene Expression, Immunology and Stress. Proceedings $X^{\text {th }}$ ISRP. Wageningen Acedemic Publishers, pp. 87-135

Van Soest P., Van Amburg M.E., Tedeschi L.O., 2000. Rumen balance and rates of fiber digestion. Proceedings of Cornell Nutrition Conference, pp. 150-166

Weisbjerg M.R., Hvelplund T., 2005. Current status of using in situ estimates in feed evaluation for dairy cows in the Nordic countries. Übers. Tierernähr. 33, 157-167 